\title{
Erratum to: Improvement in insulin resistance and favourable changes in plasma inflammatory adipokines after weight loss associated with two months' consumption of a combination of bioactive food ingredients in overweight subjects
}

\author{
Mariangela Rondanelli • Annalisa Opizzi - Simone Perna • Milena Faliva • \\ Sebastiano Bruno Solerte • Marisa Fioravanti • Catherine Klersy • \\ Edda Cava $\cdot$ Maddalena Paolini $\cdot$ Luciano Scavone $\cdot$ Paola Ceccarelli \\ Emanuela Castellaneta $\cdot$ Claudia Savina $\cdot$ Lorenzo Maria Donini
}

Published online: 13 January 2013

(C) Springer Science+Business Media New York 2013

Erratum to: Endocrine

DOI 10.1007/s12020-012-9863-0

In the original publication, the given and surnames of six of the authors were reversed. The correct authorship appears here.

The online version of the original article can be found under doi: 10.1007/s12020-012-9863-0.

M. Rondanelli $(\bowtie) \cdot$ A. Opizzi $\cdot$ S. Perna $\cdot$ M. Faliva Department of Applied Health Sciences, Section of Human Nutrition and Dietetics, Faculty of Medicine, University of Pavia, Azienda di Servizi alla Persona di Pavia, Servizio Endocrino Nutrizionale, Istituto di Riabilitazione "Santa Margherita", Via Emilia 12, Pavia, Italy e-mail: mariangela.rondanelli@unipv.it

S. B. Solerte $\cdot$ M. Fioravanti Department of Internal Medicine, Geriatrics and Gerontology Clinic, University of Pavia, "Istituto Santa Margherita",

Pavia, Italy

C. Klersy

Service of Biometry \& Clinical Epidemiology, Fondazione IRCCS “Policlinico San Matteo", Pavia, Italy

E. Cava $\cdot$ L. M. Donini

Experimental Medicine Department, Medical Physiopathology, Food Science and Endocrinology Section, Food Science and Human Nutrition Research Unit, Sapienza University of Rome, Rome, Italy

M. Paolini - L. Scavone - P. Ceccarelli - E. Castellaneta ·

C. Savina

"Villa delle Querce"' Clinical Rehabilitation Institute,

Rome, Italy 